\title{
Craig: $O$ arquitecto da cena em tempos inóspitos
}

EMÍLIA COSTA

Edward Gordon Craig, Rumo a um novo teatro \& Cena, tradução de Luiz Fernando Ramos, São Paulo, Editora Perspectiva, 2017, 272 pp.

\author{
Quando eu tiver um teatro, \\ não pretendo entrar nele armado de um plano feito pela máquina \\ sobre como tudo deve ser feito. Pois, como eu digo, \\ não sou tsar nem comunista. O teatro é como um jardim- \\ as coisas devem crescer nele de acordo com as leis da natureza \\ ajudadas pelas pequenas habilidades dos jardineiros. \\ EDWARD GORDON CRAIG
}

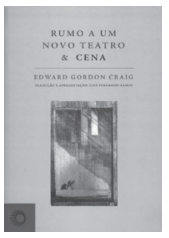

O projecto de traduzir para a língua portuguesa a obra completa de Edward Gordon Craig, imaginado por Luiz Fernando Ramos, e concretizado, finalmente, em 2017, pela editora Perspectiva, de São Paulo, Brasil, com a publicação de Rumo a um novo teatro đr Cena, o primeiro dos três livros previstos, colmata uma inexplicável ausência de tradução para português do pensamento sobre a arte teatral de uma das personalidades mais influentes da primeira metade do século Xx. Com excepção do primeiro dos seus livros, o emblemático On the Art of the Theatre, publicado em 1905, e posteriormente republicado em 1907 e 1911 com o novo nome The Art of the Theatre, nenhuma outra das suas obras teve, até então, tradução portuguesa.

Craig, nascido em 1872 em Inglaterra e falecido em 1966 em França, foi actor, gravador, encenador, cenógrafo, professor e teórico de teatro, sendo essencialmente reconhecido como criador visionário de um novo teatro, que, à época, pareceu a muitos impossível de concretizar. Na realidade, Craig apenas encenou cinco peças completamente autorais, entre 1900 e 1904, em Londres, quando o seu método - o projecto Scene - ainda se encontrava no início. Também durante alguns meses, entre 1913 e 1914, em Florença, fundou uma escola para difundir as suas ideias. As limitações a que foi sujeito impediram-no de provar a legitimidade de muitas das suas teorias, as quais, apenas no fulgor criativo da arte contemporânea, não só foram, no essencial, materializadas com 
sucesso, como, nalguns casos, se tornaram a prática dominante. Assim aconteceu com o predomínio do encenador na direcção do projecto teatral; com a utilização de telas brancas, lisas e móveis como elementos cénicos, permitindo a transição entre cenas sem o recurso ao «baixar da cortina»; com a «pintura» do cenário feita através da iluminação; e com o primado dos elementos cénicos e da luz sobre os demais elementos teatrais.

Rumo a um novo teatro \& Cena incorpora dois dos livros essenciais de Craig para entender as suas ideias sobre o novo teatro que se propunha criar; concretamente, para compreender essa grande inovação que foi o seu projecto Scene, e principia com uma excelente, rigorosa e iniciática introdução à obra do autor, assinada por Luiz Fernando Ramos, dramaturgo, encenador e professor de teatro que, de forma notável, foi o seu tradutor.

A primeira obra, com o título original Towards a New Theatre, foi publicada em 1913 e nela, como na maioria dos seus escritos, combina-se o texto com desenhos por si elaborados, representativos de imagens cénicas. Admirador confesso de Leonardo da Vinci, Craig inicia este livro com um agradecimento destacado a este artista. Prossegue, elucidando que o seu propósito é descrever o percurso que já efectuou em direcção a um novo Teatro, detendo-se num conciso resumo sobre a história da cenografia do palco, tema central do livro, onde distingue quatro períodos, o período dos Gregos (o período áureo da cenografia em que esta se construía em espaços abertos, em perfeita harmonia com a arquitectura), o período cristão (em que, apesar de a cenografia já decorrer em espaços fechados, continuava a ser banhada pela luz do Sol e em harmonia com a arquitectura), o período da commedia dell'arte (em que o cenário regressou às ruas, mantendo-se em harmonia arquitectónica), e o período do cenário pictórico (cenário pintado, elaborado para ambientes fechados, com recurso a luz artificial, e em total desrespeito pelas regras da arquitectura). Sub-repticiamente, pressente-se a existência futura de um quinto período, aquele para o qual Craig se dirige.

Os restantes capítulos até ao posfácio têm como tema um ou dois desenhos que os acompanham, se bem que, em muitos deles, Craig não lhes faça qualquer menção, advogando como filosofia que os desenhos devem «falar» por si. Nesse percurso fragmentado e por vezes desconexo, Craig aborda de uma forma cativante, original e com inteligentes pinceladas de humor a sua visão de como deve ser o teatro, tecendo simultaneamente uma forte crítica ao estado da cena teatral coeva. 
Na conversa que expressamente mantém com o leitor, Craig esclarece que o teatro seu contemporâneo perdeu o espírito de harmonia e uniformidade, reduzindo-se à imitação e artifício, com cenários de telões pintados e fixos, onde se perdeu a genuinidade e, sobretudo, o fim último de toda a arte, a Beleza. Por isso, apela às mulheres, mais sensíveis ao Belo, que o ajudem nesta sua luta pela criação de um novo teatro, rejeitando a fealdade e a nova divindade, que tudo seduz e subjuga, o «dólar». Na estóica luta para alterar o statu quo teatral, em substituição da imaginação estéril, das emoções domesticadas, das mãos ineptas e das vozes roucas, propõe imaginação criativa, emoções autênticas e um verdadeiro e inspirador espaço cénico, onde o espectador, para compreender a cena, não precisa que algo lhe seja dito, bastando-lhe ver o que «está sendo feito».

Craig ilustra, com sábia ironia, em dois pequenos episódios, não só a sua nova concepção cénica, como também a sua difícil aceitação pelos directores teatrais de então. No primeiro, ocorrido em Berlim no ano de 1904, foi-lhe pedido por um director alemão, que já tinha sido crítico literário e estudado teatro durante alguns anos, para desenhar a cenografia e os figurinos para a tragédia Veneza preservada, de Otway, adaptada livremente por Hugo von Hoffmansthal. Ao mostrar o desenho conceptualizado para a última cena, perante o olhar de suspeição do director, este perguntou-lhe onde era a porta, tendo Craig lhe respondido: «Mas não há porta, há uma entrada e uma saída», ao que o director insistiu: «Mas eu não vejo maçaneta nem fechadura. Você não pode ter uma porta sem maçaneta», tendo novamente Craig respondido: «Não há porta. Há um caminho para entrar e um caminho para sair.» Perante a súbita fúria do director em face dessa inusitada imagem cenográfica sem porta, Craig conseguiu acalmá-lo e convencê-lo, alegando que tinha copiado aquele cenário, linha por linha, de um velho manuscrito italiano. No segundo episódio, quando Craig mostrou o desenho idealizado para a primeira cena do primeiro acto de Macbeth, de Shakespeare, onde existia um pilar vertical ao centro, um actor-administrador olhou-o como se estivesse a ver um fantasma e perguntou-lhe do que se tratava, insistindo para que lhe explicasse o que é que o cenário pretendia representar, e Craig, em vez de lhe dizer que apenas pretendia «dar aos espectadores a mesma sensação no início da peça que Beethoven oferece aos ouvintes na abertura de sua Sinfonia Eroica, elucidou-o que o pilar ao centro evocava a pedra em Scone, na qual os reis da Escócia eram coroados, o que o deixou profundamente satisfeito. $\mathrm{O}$ que Craig põe em questão, em ambas 
as situações, é o domínio da razão, da autoconsciência, grande opositora da Arte, a qual apenas deve ser percepcionada sensorialmente, em harmonia com os princípios simbolistas que o autor professava.

No posfácio, de forma a acentuar a responsabilidade da estética realista na decadência teatral, Craig associa-a aos acontecimentos políticos advindos da Revolução Francesa, do comunismo na Rússia e do fim das monarquias na Alemanha e em Portugal. Estes acontecimentos trouxeram a inquietude, a agitação e a revolta do povo e, consequentemente, a fealdade da vida quotidiana para os palcos, afastando-os do seu verdadeiro ideal de Harmonia e Beleza. Porém, Craig vaticina que, no futuro, com a liberdade do teatro, relativamente ao que se deve mostrar e como o fazer, uma nova esperança existirá.

Em Cena, no original Scene, escrito em 1922 e publicado em 1923, Craig desenvolve, num modelo mais consistente e sequencial, aquilo a que denomina «a quinta cena».

Assumindo que a sua estética teatral deve conseguir expressar-se através dos seus desenhos e gravuras, já que teve poucas oportunidades de se revelar em palco, deixa, em palavras - e apesar de considerar que as mesmas perderam o significado-um testemunho sobre algumas dessas ideias.

Desenvolvendo a história da cenografia do palco que já descrevera resumidamente em Rumo a um novo teatro, mantém a divisão em quatro dramas (que mais à frente substituirá por cenas), acrescentando-lhe, porém, um quinto, ainda por realizar.

Os três primeiros são, assim, o clássico (incluindo o grego e o romano), o medieval cristão e a commedia dell'arte italiana, dignificando todos eles a arte teatral, ainda que em decréscimo de grandeza; o quarto, pictórico, mecânico e o grande responsável pelo declínio teatral; e o quinto, o seu teatro - com mil cenas numa única cena-, aquele que irá devolver a grandiosidade perdida à realidade teatral, tornando-a a maior das artes.

Dedicando o último terço do livro à explanação da quinta cena, defende a necessidade de o encenador ser o coordenador único do drama, de preferência também actor, tendo por missão simplificar o palco, pondo cada cena no seu lugar, expurgando os objectos cénicos que não sejam capazes de se exprimir. Aliás, a principal função do encenador é testar todos os elementos do drama para apurar se naquela situação em concreto possuem expressão ou não, sem rejeitar ab initio qualquer possibilidade. Daí que o encenador, apesar de ser a autoridade máxima na criação do drama, tem de saber ouvir a natureza, de forma a detectar a harmonia entre todos os elementos, por isso, ele é comparável a um 
jardineiro, cuja função é dar à natureza todas as condições para florescer. Por fim, concretizando o seu método inovador, Craig esclarece que, após reduzir todas as habitações que a humanidade construiu, desde 5000 a. C. até à actualidade, em duzentos e cinquenta modelos, estudou-os para apreender a sua essência, vindo a concluir que todas elas tinham em comum apenas chão, paredes e telhado planos, pelo que restringindo, de igual modo, a cena à sua essência, criou cenograficamente telas planas, lisas e móveis que, através do movimento e da luz que sobre elas incida, são susceptíveis de representar qualquer habitação, tanto interna como externamente, quer o «barraco de barro ou templo Palácio de Versalhes ou a loja do senhor Harrod».

Retirando do cenário quer a pintura dos telões quer uma miríade de objectos inúteis, reduzindo o espaço cénico a telões brancos, lisos e móveis, sobre os quais todas as cores, através da iluminação, podiam incidir, Craig devolveu efectivamente ao palco a dignidade e grandiosidade perdidas, o que facilmente se constata dos cinquenta e nove magníficos desenhos que compõem a obra, numa modelar impressão gráfica.

Participar na viagem narrativa deste livro permite-nos constatar que a invenção, pelo menos em artes colectivas, como é a arte teatral, para atingir a sua plenitude, para se materializar, necessita da participação de outras pessoas e do apoio económico de quem consiga visionar o futuro. Craig, nascido no meio teatral-filho de mãe actriz e de pai arquitecto que se dedicou à cenografia -, apesar de ter consagrado pelo menos vinte e cinco anos ao estudo e concepção do seu projecto Scene, nunca teve a oportunidade de o testar, na sua plenitude, por não lhe ter sido possível convocar para o seu sonho quem, possuidor dos meios necessários, tivesse arriscado na sua concretização. E, se é indesmentível não só a amargura como a arrogância do autor, que perpassa em vários momentos destes escritos, o que poderá causar algum desconforto ao leitor mais desatento, não é menos inegável a legítima frustração de um homem criativo como Craig, a quem foi negada a oportunidade de demonstrar o mérito das suas ideias, como, aliás, os anos vindouros vieram a testemunhar. E se, tal como Craig advoga, apenas o criador de uma ideia é capaz de a pôr plenamente em prática, ter-se-á perdido, para sempre, a possibilidade de testar todas as potencialidades do seu método, tal qual ele o imaginou.

A nós, contemporâneos de uma nova era, resta-nos apenas o deleite de nos perdermos nestas duas obras, incorporadas num elegante e convidativo exemplar livresco, cuja simplicidade, qualidade e beleza estética Craig teria apreciado. 